\title{
Processos de Inclusão Excludente Presentes no Ensino Superior Privado
}

\author{
Mário Luiz Ferrari Nunes' \\ Marcos Garcia Neira"
}

'Universidade de São Paulo (USP), São Paulo/SP - Brasil "Universidade de São Paulo (USP), São Paulo/SP - Brasil

RESUMO - Processos de Inclusão Excludente Presentes no Ensino Superior Privado. As pressões locais e globais por melhora nas formas de organização social incidiram em políticas públicas que visam garantir o acesso ao ensino superior de parcela da população, outrora desprivilegiada. Este artigo trata dos efeitos que esses processos de inclusão podem gerar. Os dados coletados através de uma etnografia em uma Instituição de Ensino Superior privado foram analisados mediante as noções de identidade e diferença produzidas pelos Estudos Culturais. Considera que os processos de inclusão reforçam e validam as identidades que se adéquam às imposições de consumo e performatividade, características do neoliberalismo, e marcam a diferença por meio de processos sutis de exclusão para aqueles que não se inserem na lógica social vigente.

Palavras-chave: Inclusão Social. Identidade e Diferença. Formação Inicial. Ensino Superior.

ABSTRACT - Processes of Exclusive Inclusion Present in Private Higher Education. The local and global pressures for new forms of social organization have focused on public policies aimed at granting access to higher education to a hitherto underprivileged segment of the population. This article deals with the effects that these inclusion processes can produce. The data collected through an ethnographic study in a private institution of higher education (IHE) were analyzed in the light of the concepts of identity and difference as produced by the field of Cultural Studies. The text proposes that the inclusion processes reinforce and validate only the identities that fit the imposition of consumption and performance characteristic of Neoliberalism, and signal this difference through subtle processes of exclusion of those who do not conform to the prevailing social logic.

Keywords: Social Inclusion. Identity and Difference. Initial Education. Higher Education.

Educação \& Realidade, Porto Alegre, v. 39, n. 4, p. 1209-1228, out./dez. 2014.1209

Disponível em: <http://www.ufrgs.br/edu_realidade> 
Processos de Inclusão Excludente Presentes no Ensino Superior Privado

\section{Introdução}

A luta pelo processo de democratização do acesso à escola chegou ao Ensino Superior (ES). Tal e qual ocorrem na escolarização básica, as condições para a permanência e a qualificação dos representantes dos grupos sociais desprivilegiados neste nível de ensino padecem dos mesmos problemas. O que se vê são tentativas de incorporação da diferença como se fosse o idêntico, o mesmo, a identidade (Skliar, 2002) em situações de homogeneização estabelecidas a partir da identidade normatizada destes tempos: o sujeito-cliente (Veiga-Neto, 2000).

$\mathrm{Na}$ instituição que acolheu o estudo, observou-se a presença de uma miríade de estratégias e esforços a fim de adequar seus sujeitos-clientes às formas hegemônicas de pensar e agir, que vêm sendo amplamente anunciadas na sociedade contemporânea. Torna-se importante afirmar que as estratégias formuladas não podem ser tratadas como simples ações celebratórias que enaltecem tanto a globalização, enquanto forma dominante de mudança cultural, como a presença da diversidade cultural em seu interior. Elas são vistas como fruto das transformações nas relações globais constituídas pela revolução cultural e da informação.

Por meio de suas pedagogias culturais, a formação oferecida pela instituição enalteceu temas como a negociação; a liberdade de escolha; a livre iniciativa; a eficiência; a inovação; a criatividade; a exposição pessoal e o mérito. Tudo isso parece reforçar uma mentalidade afeita às necessidades da flexibilidade e da performatividade, do empreendedorismo e do consumo. Entretanto, esses aspectos não ocorrem em um vazio. Eles são atravessados por outros significados permeados por relações de poder que transitam na vida de qualquer indivíduo sujeito às assimetrias das relações sociais e às representações decorrentes. O processo de comodificação dos sujeitos na contemporaneidade, conforme prevê Bauman (2008a), ainda não é tão poderoso assim.

Os procedimentos metodológicos buscaram inspiração na etnografia crítica proposta por Kincheloe e McLaren (2006), utilizando os instrumentos da observação, da análise documental e da entrevista com respondentes e informantes (Flick, 2009). O material empírico, aqui parcialmente apresentado, foi analisado mediante o confronto com as noções conceituais da identidade e da diferença produzidas pelos Estudos Culturais e pelos Estudos Foucaultianos.

\section{A Abertura para Inclusão}

Ao ingressar na instituição que acolheu a investigação, o estudante sujeito-cliente fica diante das metas estabelecidas tanto pelas políticas públicas para o ES, quanto pelas políticas desta entidade, que por ser privada e cumprir um papel social que lhe é característico, apresenta um caráter híbrido em que os aspectos políticos, econômicos,

1210 Educação \& Realidade, Porto Alegre, v. 39, n. 4, p. 1209-1228, out./dez. 2014 Disponível em: <http://www.ufrgs.br/edu_realidade> 
sociais e culturais se misturam. Como qualquer elemento híbrido, as partes não são anuladas. Elas convivem em uma forma de integração, onde não há fusão nem supressão de si mesmas. Estão ali, vivendo a ambivalência que caracteriza a fronteira. Trata-se de uma fronteira fluida, fragmentada, borrada, que permite o trânsito entre as partes. O que existe é uma tensão permanente em que pode haver ressurgimento de conflitos, ou domínio de uma política sobre outra a qualquer momento (Bhabha, 1998).

Essa é a paisagem em que se encontra o ES e a escolarização de um modo geral. $\mathrm{O}$ espaço em que se inserem os sujeitos da educação também é atravessado pelos valores e crenças que seus sujeitos significam em relação ao processo de transmissão e apropriação dos conhecimentos e da constituição das identidades. Como diz Silva (1995, p. 205), "[...] as identidades e as subjetividades sociais existem num terreno de indeterminação, num território de significados flutuantes”. Isso pode explicar o emaranhado que caracteriza as intenções institucionais, em que aspectos antagônicos são objetivados:

a) Missão:

"Desenvolver e formar pessoas por meio do ensino, da pesquisa e de ações humanísticas para a vida profissional e o exercício consciente da cidadania".

b) Visão:

"Ser reconhecido como um centro de excelência de formação profissional e um importante parceiro para o desenvolvimento socioeconômico e sustentável da iniciativa privada e do poder público".

c) Valores:

-Transparência e ética nas relações

-Responsabilidade social e desenvolvimento sustentável

-Princípios humanistas e igualitários

-Comprometimento com a qualidade de ensino.

Fonte: Portal da Instituição.

O que se vislumbra é a heterogeneidade de projetos, pois tenta relacionar cenários que manifestam pontos de vista ideológicos e administrativos plurais. Além da instituição não ser uma Universidade (o que a afasta de estudos referenciais desse sistema), ela expressa vocações e intenções que traduzem movimentos de luta e resistência em função dos sujeitos que lá atuam inclusive os gestores. Isso ocorre mesmo que se pesem as relações de concorrência que mobilizam suas estratégias de ação e as políticas públicas que as fazem operar. Como seus sujeitos significam as intenções da instituição? Quais são seus possíveis efeitos objetivos e subjetivos? Esses sujeitos são simples efeitos da maquinaria da globalização?

Como afirma Hall (2000, p. 108), as identidades nunca são singulares. Elas são múltiplas e “[...] construídas ao longo de discursos, práticas e posições que podem se cruzar ou ser antagônicos”. Os aspectos

Educação \& Realidade, Porto Alegre, v. 39, n. 4, p. 1209-1228, out./dez. 2014.1211 Disponível em: <http://www.ufrgs.br/edu_realidade> 
Processos de Inclusão Excludente Presentes no Ensino Superior Privado

econômicos hibridizam-se às intenções humanísticas enunciadas pela instituição e ganham materialidade na sua missão, visão e valores, nas falas de membros gestores e nas práticas sociais que ocorrem no seu interior. Nos encontros entre gestores, docentes e discentes, ouve-se com frequência que a meta institucional e o sonho que moveram o fundador, a entidade e sua própria manutenção é viabilizar a ascensão social aos alunos. Afirma-se literalmente que a intenção é preparar os alunos para serem da classe A. Nessa empreitada a meta é que o futuro egresso possa servir a sociedade e a sociedade servir-se dele ${ }^{1}$. Expressões que enunciam concepções de homem, educação e sociedade.

Nessa confusão de fronteiras entre promoção social e promoção do social, é relevante na relação entre sujeito-cliente e instituição a aproximação entre gestores e comunidade. Este procedimento é enfatizado como um diferencial da entidade e a manutenção de seu caráter humanístico na formação dos discentes. Tanto o Reitor, como os Pró-Reitores, diretores de área e coordenadores de cursos atuam em sala de aula no exercício da docência, conversam com os estudantes e professores, respondem e-mails, enfim, constroem outros significados para a posição de sujeito que ocupam. Essa prática, segundo os próprios, tenciona mostrar que a Educação não pode perder seu aspecto idealista, praticada por paixão e crença dos seus sujeitos naquilo que realizam. Algo que enaltece o caráter heroico da profissão docente.

Outro aspecto importante dessa relação é a afirmação do que é ser Humano e o modelo de inclusão propalado. Silva (2001) explica que o Humanismo fixa-se em um conjunto de pressupostos que afirmam que o homem nasce com uma essência, uma qualidade intrínseca na qual ele é o centro do universo, e a sua trajetória é a busca por si mesmo. Sua identidade é fixa, individualista, universal e totalizada. Para Hall (1998), essa concepção de sujeito dotado das capacidades de razão, consciência e ação, além de portador de um núcleo interior, é contestada a partir de uma série de deslocamentos e rupturas produzidas pelo conhecimento moderno. O ser humano propalado pelo Humanismo tem data de nascimento, uma determinada geografia e história: ele é seiscentista, europeu, branco, patriarcal, heterossexual, cristão e burguês. Isso fica ainda mais evidenciado na meta institucional de inserir os seus sujeitos na classe A, local constituído e ocupado, em geral, pelas identidades descritas.

Essas condições abrem portas para outra dimensão de análise. Apesar de "bem intencionado" e, em alguma medida, contrário aos ditames do Banco Mundial², pois este quer apenas mão de obra qualificada e consumidora de tecnologias, o discurso de inserção social dá a entender que o ES privado concebe a civilização industrial constituída nos últimos dois séculos de uma só maneira. Esquece a dinâmica que a consolidou e, principalmente, o valor das dúvidas que o próprio conhecimento acadêmico formulou a respeito das certezas das ações do homem dito civilizado.

1212 Educação \& Realidade, Porto Alegre, v. 39, n. 4, p. 1209-1228, out./dez. 2014 Disponível em: <http://www.ufrgs.br/edu_realidade> 
A inclusão social apresenta outro aspecto. Veiga-Neto e Lopes (2007, p. 947) afirmam que as políticas de inclusão, principalmente as políticas de inclusão escolar, aqui ampliada para todo o percurso de formação, "[...] são dispositivos biopolíticos para o governamento e o controle das populações". Os autores enfatizam que ao se promover uma educação para todos, corre-se o risco de realizar uma inclusão que exclui as diferenças. $\mathrm{O}$ resultado pode ser o reforço daquilo que se quer apagar.

Não há nada de errado no tocante à luta pela superação das desigualdades sociais. Promover os sujeitos historicamente desprivilegiados de bens e produtos não pode ser visto como algo indigno. A questão não é essa. As políticas de inclusão, de modo geral, tratam a diferença como diversidade. Esta é vista, sob o enfoque relativista, como um conglomerado de múltiplas identidades. Nessa condição, cada identidade tem que ser tolerada pela sua essência e impossibilidade de comparações. A diversidade afirma a lógica na qual por natureza todos somos diferentes enquanto sujeitos e iguais enquanto espécie. Nessa lógica, uns conseguem progredir na vida e outros por sua própria (in)capacidade pessoal ou cultural ficam à revelia da sociedade.

Com base em Bhabha (1998) e Skliar (2002), pode-se dizer que o diverso é outra manifestação do mesmo, pois nele estão inscritos grupos (negros, mulheres, idosos, ribeirinhos etc.) cuja estrutura que lhes dá significado foi fixada por um ato de poder, o que produziu sentidos para a identidade pela sua diferença em relação ao seu oposto. E isso significa ignorar a diferença como algo construído em meio às regulações dos sistemas de significações engendrados pelas relações de poder.

Incluir sujeitos de setores populares em classes abastadas é reforçar que o diferente, o estranho no ninho, apresenta algo indisponível aos normais. $\mathrm{O}$ resultado dessa operação tem sido o de reforçar as noções de normalidade, para os que já estavam lá e anormalidade para aqueles que foram incluídos. Logo, passíveis de serem normalizados pelos saberes especializados. Ou seja, as políticas de inclusão diferenciam os sujeitos e fazem disseminar as normas vigentes da normalidade. O que de certo modo promovem o que Veiga-Neto e Lopes (2007) denominam de inclusão excludente. É o que se extrai do discurso corrente que realça o aspecto de inclusão social acompanhado do estranhamento do discurso de transformação social. Para muitos, o segundo não difere do primeiro.

Ao enunciar que os sujeitos das classes populares C, D e E podem, via ES, ingressar na classe A, para que adquiram condições de superar a desigualdade social, sem dúvida, a instituição os insere em formas de governamentalidade que visam modificá-los, reforçando representações que lhes são distantes. Como forma de governo de si, os sujeitos se esforçam para adequar-se ao padrão afirmado como válido - o padrão classe A. Em busca de ser o que não são, visando o alcance das expec-

Educação \& Realidade, Porto Alegre, v. 39, n. 4, p. 1209-1228, out./dez. 2014.1213 Disponível em: <http://www.ufrgs.br/edu_realidade> 
Processos de Inclusão Excludente Presentes no Ensino Superior Privado

tativas sociais divulgadas pela instituição, muitos podem ficar pelo caminho. Tais premissas incitam a pensar que as ações humanísticas que formam para a vida profissional e o exercício consciente da cidadania somente serão contemplados quando os sujeitos atuarem em conformidade com os padrões da classe social dominante, pois estes parecem ser os pontos terminais do projeto educativo institucional. O que denota a contradição com os valores de formação anunciados.

A proposta, ao que parece, ancora-se em discursos históricos que associam o compromisso da qualidade com a noção de igualdade. Não se trata da tensão entre reconhecimento e distribuição, como apresentado por Fraser (2007). A impressão é que se trata de uma luta pelo controle dos discursos, logo, do significado do que venha a ser viver melhor. Afinal, para servir a sociedade e dela se servir é necessário pertencer a certo grupo e ter certos conhecimentos/formação. Sem dúvida, uma apurada observação das estruturas de avaliação, conhecimento e aprendizagem que sustentam qualquer processo de escolarização e das estratégias cotidianas que movem a instituição investigada, faz crer que a igualdade anunciada não se refere aos direitos de reconhecimento e de distribuição, mas ao rendimento, produção e homogeneidade. $\mathrm{Ou}$ seja, a formação no ES tende a ser uma ação assimiladora. Fazer valer a classe A como meta de humanidade e a visão de ser reconhecido como um centro de excelência de formação profissional e um importante parceiro para o desenvolvimento socioeconômico e sustentável da iniciativa privada e do poder público implica a produção de uma dinâmica que insere seus sujeitos em padrões que delimitam a maneira como narram a si mesmos e aos outros. Alguns iguais terão o privilégio para inscrever o Outro na representação enquanto diferença.

Isso se deve às narrações marcadas por valores desiguais, pois o contexto em que metas, missões, visões e valores são engendrados é constituído pela complexidade das relações sociais externas que influenciam a instituição, além da tensão entre as relações de exclusão e inclusão que as práticas cotidianas produzem. Portanto, as narrações são discursos constituintes de regimes de verdade, na acepção de Foucault (2006), que dependem da posição de quem os enuncia. Os discursos enunciados não são somente coercitivos com posicionamentos que não sejam típicos da classe A, (humanísticos, compromissados com a qualidade, de excelência profissional etc.), também são produtivos dessas formas de ser. O que mais uma vez indica contradições com as intenções arroladas na sua missão, valores e visão.

Se o padrão classe A pode ser visto como homogeneizado em torno de normas e condutas ocidentais, ou, talvez, estadunidenses, o questionamento interposto à presença da diferença nos bancos universitários abarca outras tensões: a sensação de pertencer a uma identidade cosmopolita, os modos de vida heterogêneos como objeto de desejo e consumo; e a produção fragmentada de novas identidades no interior

1214 Educação \& Realidade, Porto Alegre, v. 39, n. 4, p. 1209-1228, out./dez. 2014 Disponível em: <http://www.ufrgs.br/edu_realidade> 
de formas culturais hegemônicas, gerando situações de conflito e construindo novas fronteiras identitárias. O que poderá resultar dessa tensão?

O caráter ambíguo das intenções institucionais funciona como fronteira interna, em torno da qual estão marcadas as diferenças, e que, portanto, é lugar potencial de contestação quanto ao sentido da formação anunciado. Hall (2003) responde a essas tensões advogando que quando se atravessam velhas fronteiras culturais o resultado pode não ser a obliteração do velho pelo novo, mas o surgimento de alternativas híbridas que sintetizam elementos de ambas, mas não redutíveis a nenhuma delas. A ascensão da diferença social pode, quem sabe, modificar as condições de existência da classe A, bem como seus jogos de poder que investem forças para mantê-la como norma. Talvez, essa possibilidade de mudança seja o que gere as práticas de contenção do Outro por meio da valorização da mesmidade.

\section{A Negação do Outro}

A partir do momento em que se enuncia que a meta institucional é formar para inserção na classe A, afirma-se, ao mesmo tempo, que os alunos não pertencem a tal classe e a sua posição originária não é desejável nem adequada. Se for considerado que as atuais condições culturais de existência do ES privado brasileiro atraem um público bem variado, será lícito dizer que o conservadorismo que caracteriza a universidade, bem como sua expansão e acessibilidade promovem discursos contraditórios, tanto os produzidos pelos docentes acerca dos discentes, como os dos discentes acerca deles mesmos.

Os primeiros tecem elogios àqueles que empreendem esforços para graduar-se. Os alunos que frequentam o turno da madrugada ${ }^{3}$, por exemplo, são tidos pelos docentes como mais compromissados e engajados que os outros. A justificativa é a "consciência que o grupo tem em relação à necessidade de superar sua condição social”. Nos outros períodos, os destaques são pontuais. Por outro lado, as críticas mais ásperas apontam as dificuldades dos alunos em relação aos processos de aprendizagem, produção de escrita, empenho etc. Chega-se a comentar que as aulas não podem ser exigentes, pois a maioria não corresponde ao que é solicitado. Enfatiza-se que os professores têm que compreender que os estudantes da instituição são oriundos das classes sociais mais baixas e, por assim ser, tiveram uma formação básica ineficiente.

A essas críticas podem-se acrescentar significações docentes acerca das condições de moradia dos estudantes. Alguns utilizam com desprezo as expressões do outro lado do rio ou do outro lado da ponte para marcar o espaço geográfico habitado pela maioria dos discentes da instituição ou de suas condições de herança. Tanto os discursos motivacionais proferidos pelos docentes para que os alunos se dediquem

Educação \& Realidade, Porto Alegre, v. 39, n. 4, p. 1209-1228, out./dez. 2014.1215 Disponível em: <http://www.ufrgs.br/edu_realidade> 
Processos de Inclusão Excludente Presentes no Ensino Superior Privado

aos estudos, quanto às críticas a eventuais ausências no repertório desejável dos alunos tomam como base suas condições econômicas e ascendências familiares. O sujeito-cliente dessa instituição é, em geral, morador da periferia. Em certa medida, isso reforça uma concepção de multiculturalismo conservador (McLaren, 2000), que justifica um ensino pobre para o pobre, alegando que é o que pode fazer sentido em sua cultura.

Querem manter sua condição de herança? Herança de borracheiro! Se quiser mudar isso aí tem que estudar pra ganhar mais!

Na escola pública só tem filho de bandido!

Fonte: Diário de campo - depoimentos proferidos pelos alunos, reproduzindo falas de professores.

No contexto da prática, os docentes traduzem e reinterpretam as propostas institucionais e os textos oficiais, incorporando discursos de origens diversas, permeados por relações de poder marcadas por questões de gênero, raça, classe, corpo, etnia etc.

Os discursos impactantes para alunos de classes ascendentes também são formas de subjetivação. As estratégias disponibilizadas pelos professores reforçam a lógica instrumental da formação inicial e valorizam a eficiência e a visão particular/empresarial do ES. O foco do processo não é luta por justiça social, por melhores condições e reconhecimento de todos os trabalhos e profissões. O que se está a fazer é enunciar profissões com status econômicos e sociais diferenciados. Marcam-se distinções de classe e fomentam-se preconceitos. A ênfase recai na desvalorização da profissão dos familiares como algo indesejado, mais ainda para quem está no ES. Se o conhecimento não for traduzido em ganho de capital, renda ou lucro em níveis acima da média, não passará de perda de tempo e de oportunidade para a ascensão socioeconômica.

O que se vê são pedagogias que se materializam em discursos de valorização da formação individual em detrimento de uma formação participativa, coletiva. $\mathrm{O}$ efeito desejado pelo professor pode ser apenas o de fazer com que os alunos e alunas estudem sua disciplina, mas a forma como enuncia traz à tona, ou pelo menos retroalimenta, os discursos da educação como local de investimento para a obtenção de um capital privado, tal qual fora formulado pela Teoria do Capital Humano. Onde e como será que este professor aprendeu a motivar seus alunos apenas ecoando as vozes do mercado? Por que será que seus discursos não concebem a educação como um bem civil? Talvez seja essa uma estratégia de segregação de sujeitos do espaço que lhes foi aberto, um exemplo do fenômeno que Neira (2008) denominou contragolpe social.

1216 Educação \& Realidade, Porto Alegre, v. 39, n. 4, p. 1209-1228, out./dez. 2014. Disponível em: <http://www.ufrgs.br/edu_realidade> 
Nas concepções de Foucault (2008), a introdução da grade econômica como bastião das análises de todo o comportamento social foi uma das estratégias de implementação do pensamento neoliberal no século XX. Surge o sujeito de interesse que terá como princípio de inteligibilidade compreender as relações sociais unicamente através da economia. O que passa a valer é o sujeito individual, empreendedor de si mesmo. As falas docentes tanto reforçam a identidade do empreendedor de si mesmo, constantemente incentivadas pela instituição, como marcam a diferença de classe e de profissão. O resultado provável é o seguinte silogismo: se eu não estudar, não ganho; se eu não estudar e não ganhar, logo, serei como meu pai, cuja profissão não é digna de herança; se não estudar e não ganhar, logo, não serei ninguém; meu pai é ninguém.

Giroux (2003) responde com uma crítica contundente. Discursos como esse impossibilitam falar sobre a vida pública fora da lógica do mercado. Por sua vez, McLaren (1997) diria que os professores, sem perceber, acabam por exercer formas de violência simbólica, impondo uma condição de classe e desvalorizando experiências e vidas de estudantes oriundos de grupos minoritários - o maior contingente da instituição. Isso fica ainda mais problemático quando se enuncia que na escola pública só tem filho de bandido. Tanto a maioria dos alunos é proveniente do sistema público de ensino, quanto é visível a crescente presença de sujeitos no ES cuja história de vida não se enquadra nos parâmetros hegemônicos. E como fica o filho do bandido, que até pode estar lá na sala de aula silenciado pela sua condição, e os sujeitos contraventores? Por acaso, não têm direito à educação?

Em meio à formação do sujeito-cliente da sociedade contemporânea, há a irrupção dos outros, do estranho, do sujeito da periferia. Rapidamente, a formação se transforma em uma narrativa sobre aquele que é o distante, que ao mesmo tempo está muito próximo. Sem dúvida, isso faz com que o ES consolide-se como um território cultural em que se tenta manter representações dominantes e, simultaneamente, conjurar a autoridade de representar.

Os discursos proferidos assumem um caráter performático e na medida em que sua enunciação é repetida, acabam por produzir o fato. $\mathrm{O}$ que se produz é o Outro, de outro jeito, talvez, no mesmo lugar. $\mathrm{O}$ interessante é que, ao contrário de outros tempos, no atual momento sócio-histórico do ES isso é feito de corpo presente. Nos dizeres de Skliar (2002), o Outro massacrado historicamente continua sendo culpabilizado pelo seu próprio massacre. Ao enunciar diversas vezes características identitárias para um grupo social ou sujeito, mais do que descrever uma situação se está a reforçar a identidade. Se já não bastasse a condição menor de ser aluno, ser do outro lado do rio, oriundo de uma escola na qual só estuda filho de bandido ou ser filho de borracheiro não são apenas simples descrições. O que se está a fazer é posicionan-

Educação \& Realidade, Porto Alegre, v. 39, n. 4, p. 1209-1228, out./dez. 2014.1217 Disponível em: <http://www.ufrgs.br/edu_realidade> 
Processos de Inclusão Excludente Presentes no Ensino Superior Privado

do os sujeitos em um sistema de significações que reforça relações de poder no tocante ao local de moradia, à ascendência familiar, à classe social, em suma, à sua condição histórica de vida. Para agravar a situação, negam-se as condições de existência desses sujeitos. As tentativas de incluir o Outro na lógica do consumo e do empreendedorismo passa, necessariamente, pela redução de sua condição de ser desalojado, anormal, sem ancestralidade. É nessa prática de significação que o sujeito da periferia vivencia a ambiguidade da fronteira, em que os usos da sua presença trafegam entre a condição travestida de cliente e a de ser violentamente fixado na sua diferença.

De qualquer modo, o sujeito da periferia não pode ser descartado, pois é central à organização da empresa. Em torno dele giram esforços e objetivos. Em explanação de uma assessora contratada para orientar os docentes na implementação de mudanças curriculares, visando consolidar o processo de expansão da instituição, a palestrante enfatizou que as aulas devem ser ministradas em acordo com o público. Ressaltou que ali era um espaço para formar trabalhadores e não líderes e que as competências necessárias a serem desenvolvidas eram as essenciais à empregabilidade ${ }^{4}$. Ou seja, o lugar que o sujeito-cliente da periferia ocupará no mundo do trabalho já está determinado, assim como quem serão seus compradores. Essa explanação também indica o caráter ambíguo do ES privado. Ao mesmo tempo que afirma a inserção social de seus sujeitos na classe A, a entidade contrata alguém que afirma o ES como forma de fixação de identidades de sujeitos em outra classe. O que só faz recrudescer a função social da escola como espaço de seleção e hierarquização dos sujeitos, faceta criticada pela sociologia da educação desde os anos 1960 .

A presença do sujeito da periferia produz mais. Também é notória a repetibilidade dos discursos que enfatizam a pouca capacidade reflexiva dos alunos quando o assunto é a exigência da compreensão de textos científicos e dos que atribuem ao mercado à condição de selecionar os melhores. Trata-se de discursos que circulam sem cerimônia entre professores de todos os cursos e, claro, não são uníssonos. Ambos, elogios ou críticas, se referem às condições de origem e formação básica inadequada dos estudantes, realçando contraditórias posições de valorização, intolerância e complacência. O que evidencia que os discursos que realçam a meta de inserção dos alunos na classe A são, muitas vezes, solapados na prática educativa. Afinal, os docentes também são sujeitados às confusões entre metas pessoais, educativas, econômicas, sociais, políticas etc..

Na lógica neoliberal, a melhor solução para a gestão administrativa educacional seria a reforma de objetivos, métodos de ensino e conteúdos, adequando-os à gestão da qualidade total. A participação do sujeito-cliente deveria ser elaborada a partir das suas necessidades e desejos. Melhor dizendo, às necessidades do mercado, pois, o ensino, representado como produto a ser consumido, é construído para o

1218 Educação \& Realidade, Porto Alegre, v. 39, n. 4, p. 1209-1228, out./dez. 2014 Disponível em: <http://www.ufrgs.br/edu_realidade> 
mercado comercial. Nessa operação são necessários operários especializados na produção e divulgação do produto institucional, de maneira a despertar o interesse dos consumidores. Não é por acaso o caráter híbrido dos discursos docentes.

\section{As Tentativas de Regular o Outro}

No entre lugares da fronteira cultural, no centro da sua ambivalência, em que, de um lado, busca atingir sua meta social e, do outro, procura manter-se enquanto empresa com fins lucrativos, a instituição afirma deparar-se com a questão da baixa qualidade da escolarização da comunidade estudantil e a problemática dos processos avaliativos externos. Considerando que isso possa prejudicar o objetivo de formar sujeitos ajustados à lógica da competitividade, abriu-se mais uma via para que a diferença seja inventada, traduzida e governada.

A partir de olhares regulatórios, a instituição formulou um projeto que suprimiu a debilidade anunciada da formação básica, ofertando aos seus sujeitos a possibilidade do prosseguimento de estudos, conforme se verifica no comunicado abaixo:

Comunicamos que foi aprovado pela Mantenedora do [...] a continuidade das Oficinas de Língua Portuguesa e Matemática, a partir de 10 de Abril de 2010, observando-se:

1- Essas Oficinas ficarão sob a gestão da área de Educação, sob a coordenação da [...], que destaca:

"As Oficinas propostas apresentam como característica básica o resgate e a compreensão efetiva dos conceitos das duas áreas de conhecimento";

"Nos Dados oficiais da Prova do SARESP - Sistema de Avaliação da Rede de Ensino do Estado de São Paulo, as duas áreas apresentam enorme defasagem com dados alarmantes que comprovam que os alunos concluintes do Ensino Médio (antigo Colegial) não estão aptos a responder questionamentos sobre conteúdos da $8^{a}$ série do Ensino Fundamental II (antigo Ginásio)".

"A Secretaria da Educação de São Paulo implantou Curso de Capacitação específico para os Professores de Matemática, com o objetivo de suprir a defasagem na aprendizagem".

2- Temos que entender essa realidade crítica na formação de nossos alunos, mas, ao mesmo tempo tomar iniciativas ou empreender ações estratégicas que tenham por meta resolver essas deficiências para torná-los aptos para prosseguimento de seus estudos no Ensino Superior e, mais adiante, em suas respectivas áreas de atuação profissional.

3 - As Oficinas ocorrerão, a princípio, apenas aos sábados, manhã (9h às 12h) e tarde (13h às 16h), para atingir o maior número possível de alunos.

4- A divulgação e inscrições serão feitas via [...].

5- Solicitamos aos professores que divulguem essa proposta em suas respectivas salas de aula.

Fonte: mensagem eletrônica encaminhada aos docentes.

Educação \& Realidade, Porto Alegre, v. 39, n. 4, p. 1209-1228, out./dez. 2014.1219

Disponível em: <http://www.ufrgs.br/edu_realidade> 
Processos de Inclusão Excludente Presentes no Ensino Superior Privado

Esses ditos e práticas ecoam as reformas do sistema universitário brasileiro e da educação em geral. Os documentos publicados pelo Banco Mundial para implementar as mudanças educacionais nos anos 1990 reforçam a necessidade da introdução da população de baixa renda no ES como única possibilidade para que os países do chamado Terceiro Mundo possam competir no mercado global e, desse modo, participar da sociedade do conhecimento. A publicação responsabiliza os próprios países caso não alcancem a meta. Para Barreto e Leher (2008), as ações implementadas pelo Banco Mundial forjam realidades. Afirmam o que é melhor para o mundo. Caberá a cada nação ajustar-se ao modelo gestor imposto. Por meio de relações assimétricas de coerção econômica, o Banco Mundial estabelece as condições funcionais para os Estados nacionais, principalmente os periféricos, e as atrela aos interesses geopolíticos dos países centrais e aos econômicos das grandes corporações. Dentre as estratégias eleitas, ressalte-se o convencimento da sociedade de que as soluções apresentadas são as melhores para a atual situação cultural, social, política e econômica.

Outro ponto de destaque do projeto são as disciplinas ofertadas nas oficinas. Já é de largo conhecimento a ênfase dada à Matemática e Língua Portuguesa nos processos avaliativos externos da Educação Básica. Tamanho esforço para que os alunos dominem essas áreas do conhecimento, entendidas como essenciais para a formação humana, pode ser atribuído à relação próxima com as atividades profissionais ligadas às ocupações de serviços. Qualquer outra área de conhecimento fica submetida à condição de coadjuvante dos processos de formação. Se outros conhecimentos disciplinares são preteridos, o que dizer dos conhecimentos subjugados ou não disciplinares. Não há qualquer interesse em nivelar esses aspectos.

Tais estratégias reverberam fortemente nos espaços educativos. Ao ouvir repetidamente que suas experiências na formação básica foram precárias, um aluno pode assumir para si a importância de voltar no tempo e investir esforços para corrigir o possível déficit, participando desse momento corretivo de formação.

Vemos aqui a mola propulsora para outra forma de subjetivação do sujeito-cliente da periferia ou não. A negação do autoconhecimento é fomentada durante todo o curso, levando o sujeito a inventar a necessidade de investimentos constantes em sua formação. A promoção da inserção dos alunos na lógica empresarial e do consumo dá-se também pelo apagamento das insuficiências do ES. A necessidade de aperfeiçoar-se e especializar-se no interior do sistema universitário - na própria instituição, é propagada com bastante frequência. Sem perceber os mecanismos e inconsistências de um raciocínio baseado no descarte, nem tampouco dos processos maquínicos que constituíram suas insuficiências, o sujeito-cliente aprende que os conhecimentos adquiridos estão ultrapassados. Para atualizar-se, terá que fazer um curso de aperfeiço-

1220 Educação \& Realidade, Porto Alegre, v. 39, n. 4, p. 1209-1228, out./dez. 2014 Disponível em: <http://www.ufrgs.br/edu_realidade> 
amento ou especialização, pois a produção de novos saberes é extremamente veloz. Com isso, amplia-se a comodificação da educação e dos seus sujeitos mediante as afirmativas de prosseguimento de estudos.

Para obter sucesso na vida em tempos de consumismo, o sujeito-cliente depende da velocidade com que se livra de hábitos antigos mais do que adquire novos (Bauman, 2008b). Precisa livrar-se da formação anterior, das crenças e valores que construiu, internalizar novos modos de atuar, além de aprender que nestes tempos o hábito a ser aprendido é viver sem hábitos, com exceção, claro, do hábito de consumir. A cada curso, a cada investimento, o sujeito-cliente da periferia substitui saberes antigos pelos novos. A educação no ES precisa dessa lógica para consolidar-se. Nas condições presentes, as iniciativas de formação contínua tornaram-se imprescindíveis à sua subsistência. Ao que tudo indica, quando organiza momentos de nivelamento de conhecimentos, a instituição colabora para que o gerenciamento internacional de sujeitos, do qual fala Bauman (2008b), torne-se um fato natural da educação local.

As estratégias de regulação não param por aí. Do mesmo modo que nas outras práticas descritas, o projeto apresentado contribui como forma de empoderamento dos discursos neoliberais. O Estado não fez por eles, propiciou-lhes uma Educação Básica de baixa qualidade, mas o setor privado faz, e faz melhor. É provável que esse modelo de estudo enalteça as práticas discursivas contra a educação pública (e todo o sistema público) e ainda colabore para a fixação da educação terciária. Condição que reforça "[...] expressões de autoconsciência burguesa, disfarçadas em discurso popular, produzidas no interesse do povo” (McLaren, 2000, p. 292), como as propagadas pelos professores.

Os discursos proferidos por parcela dos docentes denotam que condições de classe e hierarquia não são resultados de competições e relações neutras entre os seres, mas decorrentes de arranjos sociais assimétricos e das relações de poder. É nessa microestrutura de poder e privilégio que se ressalta o paradoxo da democracia contemporânea, pois ao ignorar as características particulares dos sujeitos, reforça-se um certo universalismo.

O mesmo processo de assimilação e homogeneização é percebido nas falas dos discentes. As identidades dos estudantes do turno vespertino são forjadas de modo negativo. São vistos como filhinhos de papai ou burguesinhos, pois, para muitos, quem estuda à tarde não precisa acordar cedo para trabalhar. Não é de hoje que a identidade é marcada por questões referentes à ocupação profissional. As atuais representações sofrem intercorrências das consequências sociopolíticas e econômicas de um mercado global em que a produtividade é a lógica. Muitos alunos, de outros períodos, dizem que estudar no meio da tarde atrapalha o ritmo de vida, corta o dia e prejudica o trabalho. Já para outros, tanto faz estudar à tarde ou bem cedo, pela manhã, pois o que está em

Educação \& Realidade, Porto Alegre, v. 39, n. 4, p. 1209-1228, out./dez. 2014.1221 Disponível em: <http://www.ufrgs.br/edu_realidade> 
Processos de Inclusão Excludente Presentes no Ensino Superior Privado

jogo é melhorar de vida e, para isso, é necessário possuir um diploma de ES. Sem esquecer as condições financeiras que determinam a presença dos sujeitos em horários distintos, pois as mensalidades têm valores diferenciados e a possibilidade de adequar seus horários de estudo às ofertas laborais do mercado. Há ainda as condições sociais para a consecução dos estudos. Para muitos, o que importa é a certificação.

Os embates entre os sujeitos demonstram como ocorre a construção cultural dos processos de diferenciação da identidade e da diferença. Os discursos proferidos produzem efeitos de fronteira que estabelecem o limite entre o eu e o Outro. Entre o professor e o aluno, entre sujeitos de classes sociais diferentes, entre sujeitos capazes e incapazes, entre os que trabalham e os que não, entre aqueles que trabalham em certos lugares e horários, entre os que estudam e os que dão um jeito. São situações de dominação em que o grupo (ou o indivíduo) dominante estigmatiza uma identidade negativa para o outro, pois o poder de identificar depende do lugar que se ocupa nos sistemas relacionais que ligam os diversos grupos e sujeitos. São expressões de relações de poder produzidas em ações que oprimem certa parcela de indivíduos e grupos, que silenciam suas vozes, histórias e anseios. Essas questões implicam a manutenção do discurso superior e colonialista, cuja característica é a dependência do conceito de fixidez, signo da diferença cultural, que "[...] garante a repetibilidade em conjunturas históricas e discursivas mutantes” (Bhabha, 1998, p. 106).

\section{O Outro enquanto Mercadoria}

O ES privado brasileiro, ao assumir para si a formação de ampla parcela de identidades subalternizadas, apresenta diversas condições de negociação entre o capitalismo contemporâneo, os cânones dominantes e as políticas de identidade dos grupos desprivilegiados. O resultado parece ser a transformação da diferença em objeto. No caso da instituição investigada isso não é diferente, apenas variam suas particularidades nas formas de atuar.

1222 Educação \& Realidade, Porto Alegre, v. 39, n. 4, p. 1209-1228, out./dez. 2014 Disponível em: <http://www.ufrgs.br/edu_realidade> 
Comunicamos que agora TODAS as salas de aula do [...] passam a ter um nome "escrito em aramaico com o seu respectivo significado".

Ações estratégicas como essas possibilitam um conhecimento sistêmico de outros povos, seus usos e costumes e nos permitem refletir sobre a tão discutida pluralidade cultural.

É nesse contexto que estaremos implantando a partir de março de 2010 o Centro de Pesquisas Integrativas e de Terapias Complementares; com os seguintes objetivos:

Ser um Centro de referência internacional, a partir de espaço interdisciplinar e multidisciplinar de estudos integrativos e de terapias complementares.

Conceder espaço para leituras, reflexões, pesquisas, desenvolvimento de trabalhos, entre outras iniciativas, em caráter permanente; os doze meses do ano.

O espaço estaria estruturado com boxes, tipo consultório ou sala de atendimento, de pequeno porte e uma sala com cerca de 15 a 20 cadeiras para apresentações de palestras específicas.

Firmar convênios com associações ou instituições formalmente constituídas em ares de pesquisa e de desenvolvimento de trabalhos científicos.

Essas Associações manteriam representantes, literaturas e trabalhos formais no [...] para as atividades propostas.

A princípio pretendemos abranger: Antroposofia - Feng shui - Osteopatia - Homeopatia - Holismo - Rolfing - Acupuntura - Projeciologia - Interdisciplinaridade, entre outras áreas de pesquisa.

Lançar publicações nessas áreas em parcerias com as respectivas instituições.

Manter uma revista com essa diversidade.

Fonte: mensagem eletrônica enviada à comunidade.

Na sociedade de consumo, a celebração das diferenças, difundida pela política contemporânea de cidadania multicultural, foi rapidamente absorvida pelo capitalismo e introduzida como nova forma de consumo. É nessa paisagem sócio-histórica que Hall (1997) enfatiza que a cultura global depende da diferença para prosperar. Mas, mesmo com a valorização discursiva da diversidade cultural, ao convidar o outro para entrar em sua casa enfrenta-se o perigo e os riscos de conviver com a diferença. O que se tem é uma luta entre a política de representação, que visa colocar a diferença no cenário cultural e a estetização de suas imagens para colocá-las à venda no supermercado cultural das identidades (Bauman, 2008a; Hall, 1997).

No jogo de inclusão da diversidade parece que nem todas culturas interessam, ou, caso interessem, não são nomeadas nem sua presença é divulgada.

Educação \& Realidade, Porto Alegre, v. 39, n. 4, p. 1209-1228, out./dez. 2014.1223 Disponível em: <http://www.ufrgs.br/edu_realidade> 
Processos de Inclusão Excludente Presentes no Ensino Superior Privado

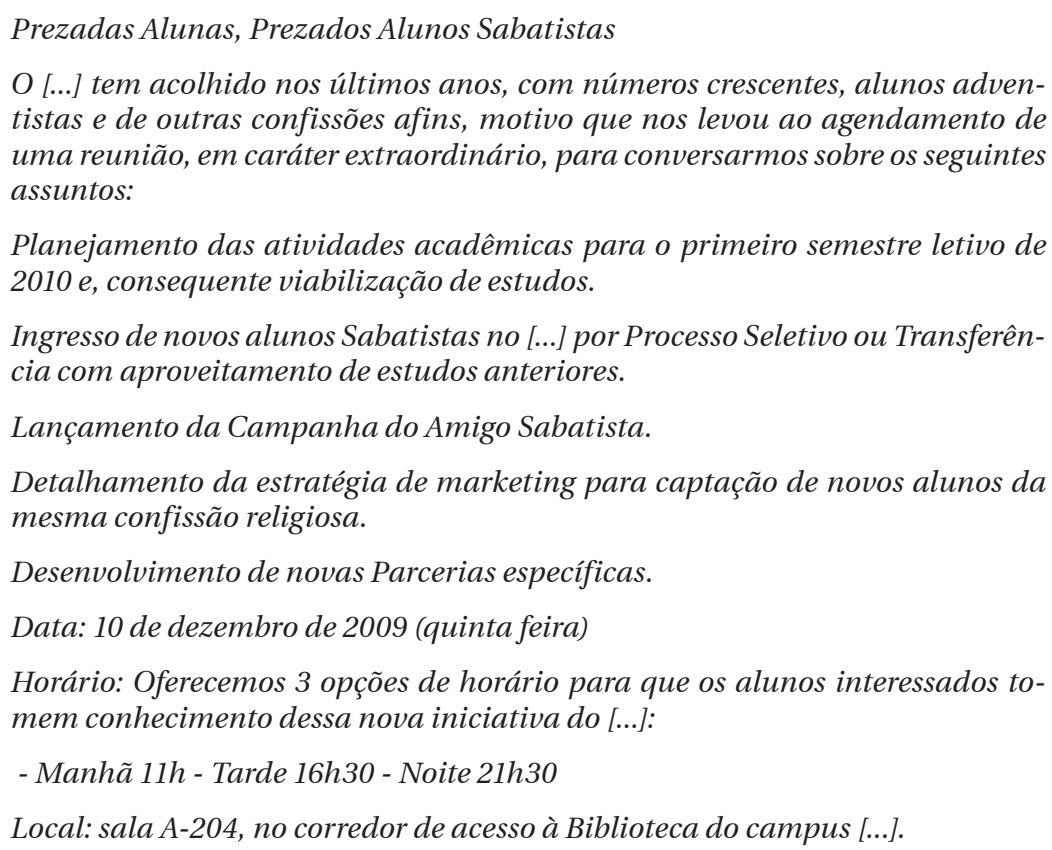

O [...] tem acolhido nos últimos anos, com números crescentes, alunos adventistas e de outras confissões afins, motivo que nos levou ao agendamento de uma reunião, em caráter extraordinário, para conversarmos sobre os seguintes assuntos:

Planejamento das atividades acadêmicas para o primeiro semestre letivo de 2010 e, consequente viabilização de estudos.

Ingresso de novos alunos Sabatistas no [...] por Processo Seletivo ou Transferência com aproveitamento de estudos anteriores.

Lançamento da Campanha do Amigo Sabatista.

Detalhamento da estratégia de marketing para captação de novos alunos da mesma confissão religiosa.

Desenvolvimento de novas Parcerias específicas.

Data: 10 de dezembro de 2009 (quinta feira)

Horário: Oferecemos 3 opções de horário para que os alunos interessados tomem conhecimento dessa nova iniciativa do [...]:

- Manhã $11 h$ - Tarde 16h30 - Noite 21 h30

Local: sala A-204, no corredor de acesso à Biblioteca do campus [...].

Fonte: mensagem eletrônica enviada à comunidade educativa.

As terapias sugeridas ou os escritos em aramaico possibilitam a aprendizagem da cultura de outros povos e a reflexão acerca da pluralidade cultural? Só existem essas terapias e expressões? Por que há esforços em agregar alunos sabatistas? E os das outras religiosidades, onde ficam? Por que não há campanhas para agregá-los? Outros grupos não apresentam formas de organização comunitária capaz de negociar a formação universitária de seus sujeitos? Não há respostas precisas para essas questões. De concreto, o que se vê é o jogo da captura de sujeitos-clientes envolver superficialmente temas candentes na Educação como interdisciplinaridade e respeito a pluralidade cultural, reforçando o diálogo entre culturas e entre elas e o ES mediado por interesses privados.

Nesse jogo, a presença/ausência de sujeitos e práticas culturais também pode ser vista como uma forma de negação de certos sujeitos e da sua cultura e a valorização de outros, o que caracteriza o antagônico jogo de captura dos sujeitos da educação e a produção da identidade e da diferença. Em alguma medida, ao introduzir e enaltecer a presença da diversidade cultural em seu interior, a instituição potencializa a criação de um tipo de sujeição cooperante dos indivíduos às práticas hegemônicas do mercado que, por sua vez, legitimam estruturas de dominação. Disso pode resultar, que o interesse próprio dos sujeitos dos grupos

1224 Educação \& Realidade, Porto Alegre, v. 39, n. 4, p. 1209-1228, out./dez. 2014 Disponível em: <http://www.ufrgs.br/edu_realidade> 
lembrados solape ou não os faça entrar em contato com os problemas ou dores da vida dos esquecidos. Por meio de mecanismos simbólicos dessa ordem, promove-se a legitimação da diversidade e propicia a sua confusão com a diferença, naturalizando-a.

\section{Finalizando}

Nota-se que o discurso do ES privado para com o sujeito da periferia constrói e mantém, com diversas estratégias, um processo que tenta fixar e estabilizar a identidade do sujeito-cliente e, ao que tudo indica, com a pretensão ser um referencial absoluto. Além disso, o ES e seus dispositivos funcionam como um processo de subjetivação que produz sobre esse sujeito, ao mesmo tempo, o desejo (econômico) de sua presença e a desconfiança, se não o escárnio, de sua condição cultural. Entre tapas e beijos, as articulações entre as políticas públicas de inclusão, as ofertas apresentadas pelos gestores da instituição e as práticas docentes para com o sujeito-cliente da periferia realçam o caráter cambiante, fragmentado e contraditório destes tempos.

Nessa luta por significações, também não se pode negar que o jogo entre os processos regulatórios das agências governamentais, a concorrência entre as Instituições de Ensino Superior e a presença de sujeitos da periferia no ES privado formulam processos antagônicos na dinâmica do jogo do poder cultural. Pode-se supor que quanto mais risco da desistência ou evasão, mais estratégias para evitar que isso ocorra são empreendidas. Quanto mais distante se quer que ele fique, mais sua presença é desejada. A partir da chance da presença, sejam os lembrados ou os esquecidos, os valorizados ou os negados, ou do prosseguimento de estudos, sejam iniciais ou posteriores, a identidade do sujeito da periferia pode cruzar fronteiras entre territórios simbólicos diferentes. Pode ser a oportunidade de resistência contra qualquer ideia de fixação de identidades.

Para melhor compreensão dessa possibilidade, estendemos as análises de Bhabha (1998). A presença do sujeito da periferia, o Outro da educação, no ES pode ser compreendida como uma temporalidade performática, que para ele significa a negação de qualquer referência a um passado brilhante. Ao mesmo tempo, o ES apresenta uma temporalidade continuísta, que seria o conjunto de saberes culturais legitimados transmitidos em um movimento contínuo e repetitivo, tal e qual o projeto que favorece o prosseguimento dos estudos. Nesse jogo entre a continuidade e a performatividade surge uma zona de ambivalência, um espaço-tempo em que é possível pensar a existência do Outro sem ser representado pelas culturas legitimadas presentes no ES por um pseudo-passado glorioso ou uma posição de supremacia cultural.

Ele está lá na própria temporalidade introduzida pela possibilidade da sua presença. Uma temporalidade que, na expressão de Bhabha

Educação \& Realidade, Porto Alegre, v. 39, n. 4, p. 1209-1228, out./dez. 2014.1225 Disponível em: <http://www.ufrgs.br/edu_realidade> 
Processos de Inclusão Excludente Presentes no Ensino Superior Privado

(1998, p. 213), é um entre lugar que permite que as vozes marginais, da periferia, “[...] não mais necessitam dirigir suas estratégias de oposição para um horizonte de 'hegemonia', que é concebido como horizontal e homogêneo".

Nessa temporalidade, podemos conceber que nenhum processo escolarizante poderá ser meramente de assimilação do Outro, do controle das populações em busca de um estado de equilíbrio social. Tampouco, nenhum processo escolarizante será capaz de impedir a construção de processos disruptivos, de criação, de abertura ao novo. Ou seja, nada garante que intenções institucionais, mercantis e governamentais sejam significadas por seus sujeitos-clientes sem que ocorram processos de traduções, desterritorializações e reterritorializações permanentes, impedindo o êxito de qualquer processo de fixidez de significados. No jogo da inclusão versus exclusão, isso fica evidente quando o sujeito-cliente e instituição negociam interesses econômicos (estratégias de captura e manutenção de clientes), acadêmicos (processos avaliativos internos e externos, a conclusão do curso), profissionais (seleção para o mercado de trabalho, bolsas de estágio, vagas em empresas parceiras, indicações etc.) e pessoais (problemas pessoais e os decorrentes da formação básica que podem incidir na participação e aprendizagem do sujeito-cliente).

Os dados apresentados não se constituem em um processo somente no plano do pensamento, das intenções, mas como reitera Hall (1997), atuam sobre a regulação das relações e sobre a própria prática social. Para o autor, é através do uso que fazemos das coisas, ou como as integramos em nossas práticas cotidianas, que damos significado às coisas do mundo. Ou seja, a representação depende da estrutura de significados construída culturalmente. As questões, então, passam a ser: como se edificam as representações da diferença dos grupos lembrados e esquecidos nas campanhas de adesão e plubicização que permeiam o ES? Quais são os seus efeitos?

Apesar de a evidente tendência cultural dominante reforçar processos globalizantes de homogeneização política, cultural e de mercado, ela "[...] não pode controlar ou saturar tudo dentro de sua órbita" (Hall, 2003, p. 59). O resultado tem sido, segundo Hall (2003), a convivência dos sistemas globais com os localismos que eles próprios produzem. Em geral, o resultado desse processo tem sido a transformação de ambos. O ES e suas práticas de adequação, enquanto espaço-tempo de fronteira e, portanto, como híbridos culturais, tanto fortalecem certos grupos como potencializam resistências. Afinal, é nesse movimento entre o mesmo e o Outro que a diferença aparece na negociação com as estruturas que a produz e insistem em negar seus modos de ser, pensar e agir, como as aqui descritas.

Com certeza, essas análises incitam um compromisso permanente com a pesquisa empírica, promovendo questionamentos acerca das

1226 Educação \& Realidade, Porto Alegre, v. 39, n. 4, p. 1209-1228, out./dez. 2014 Disponível em: <http://www.ufrgs.br/edu_realidade> 
estruturas sociais e políticas que impactam sobre a vida das pessoas, seus desejos e ideais de realização.

Recebido em 14 de agosto de 2013 Aprovado em 06 de março de 2014

\section{Notas}

1 Fonte: Diário de campo - falas proferidas por um dos Pró-Reitores em reunião com todo o coletivo docente.

2 Como parte das reformas dos anos 1990, o Banco Mundial fez exigências ao governo brasileiro para a inserção de parcela da população, outrora excluída, no Ensino Superior a fim de melhorar a qualificação da mão de obra frente às novas exigências do mercado de trabalho.

3 As aulas desse turno iniciam às 5 h45.

4 Fonte: diário de campo.

\section{Referências}

BARRETO, Raquel Goulart; LEHER, Roberto. Do Discurso e das Condicionalidades do Banco Mundial, a educação superior "emerge” terciária. Revista Brasileira de Educação, Rio de Janeiro, v. 13, n. 39, p. 423-436, set./dez. 2008.

BAUMAN, Zygmunt. Vida para Consumo: a transformação das pessoas em mercadorias. Rio de Janeiro: Jorge Zahar Editora, 2008a.

BAUMAN, Zygmunt. A Sociedade Individualizada: vidas contadas e histórias vividas. Rio de Janeiro: Jorge Zahar Editora, 2008b.

BНАВНА, Homi K. O Local da Cultura. Belo Horizonte: Ed. UFMG, 1998.

FLICK, Uwe. Introdução à Pesquisa Qualitativa. Porto Alegre: Artmed, 2009.

FRASER, Nancy. Reconhecimento sem Ética. São Paulo: Lua Nova, n. 70, p. 101138, 2007.

FOUCAULT, Michel. A Ordem do Discurso. São Paulo: Loyola, 2006.

FOUCAULT, Michel. O Nascimento da Biopolítica. São Paulo: Martins Fontes, 2008.

GIROUX, Henry. Atos Impuros. Porto Alegre: Artmed, 2003.

HALL, Stuart. A Centralidade da Cultura: notas sobre as revoluções de nosso tempo. Educação e Realidade, Porto Alegre, Universidade Federal do Rio Grande do Sul, v. 22, n. 2, p. 15-46, 1997.

HALL, Stuart. A Identidade Cultural na Pós-Modernidade. Rio de Janeiro: DP\&A, 1998.

HALL, Stuart. Quem Precisa de identidade? In: SILVA, Tomaz Tadeu (Org.). Identidade e Diferença: as perspectivas dos estudos culturais. Petrópolis: Vozes, p.103-133, 2000.

HALL, Stuart. A Questão Multicultural. In: HALL, Stuart. Da Diáspora: identidades e mediações culturais. Belo Horizonte: Editora UFMG, Brasília: Representações da Unesco no Brasil, p. 51-100, 2003.

KINCHELOE, Joe Lyons; MCLAREN, Peter. Repensando a Teoria Crítica e a Pesquisa Qualitativa. In: DENZIN, Norman K; LINCOLN, Yvonna S. et al. O Plane-

Educação \& Realidade, Porto Alegre, v. 39, n. 4, p. 1209-1228, out./dez. 2014.1227 Disponível em: <http://www.ufrgs.br/edu_realidade> 
Processos de Inclusão Excludente Presentes no Ensino Superior Privado

jamento da Pesquisa Qualitativa: teorias e abordagens. Porto Alegre: Artmed, p.281-313, 2006.

McLAREN, Peter. A Vida nas Escolas: uma introdução à pedagogia crítica nos fundamentos da educação. Porto Alegre: Artmed, 1997.

McLAREN, Peter. Multiculturalismo Revolucionário: pedagogia do dissenso para novo milênio. Porto Alegre: Artmed, 2000.

NEIRA, Marcos Garcia. A Educação Física em Contextos Multiculturais: concepções docentes acerca da própria prática pedagógica. Currículo sem Fronteiras, Lisboa, v. 8, n. 2, p. 39-54, jul./dez. 2008.

SKLIAR, Carlos. A Educação que se Pergunta pelos Outros: e se o outro não estivesse aqui? In: LOPES, Alice Casimiro; MACEDO, Elizabeth. Currículo: debates contemporâneos. Série Cultura, Memória e Currículo, v. 2, São Paulo: Cortez, p. 196-215, 2002.

SILVA, Tomaz Tadeu. Currículo e identidade social: territórios contestados. In: SILVA, Tomaz Tadeu (Org.). Alienígenas na Sala de Aula: introdução aos estudos culturais em educação. Petrópolis: Vozes, 1995. P. 190-207.

SILVA, Tomaz Tadeu. O Currículo como Fetiche: a poética e a política do texto curricular. Belo Horizonte: Autêntica, 2001.

VEIGA-NETO, Alfredo. Educação e Governamentalidade Neoliberal: novos dispositivos, novas subjetividades. In: PORTOCARRERO, Vera; CASTELO BRANCO, Guilherme (Org.). Retratos de Foucault. Rio de Janeiro: Nau, 2000. P. 179-217.

VEIGA-NETO, Alfredo; LOPES, Maura Corcini. Inclusão e Governamentalidade. Educação e Sociedade, Campinas, v. 28, n. 100 - Especial, p. 947-963, out. 2007. Disponível em: <http://www.cedes.unicamp.br>. Acesso em: 01 jun. 2008.

Mário Luiz Ferrari Nunes é licenciado em Educação Física com Mestrado e Doutorado em Educação pela Faculdade de Educação da USP. Coordena o Grupo de Pesquisas em Educação Física escolar Gpef - FEUSP/CNPQ. E-mail: mario.nunes@usp.br

Marcos Garcia Neira é licenciado em Educação Física e Pedagogia com Mestrado e Doutorado em Educação, Pós-doutorado em Currículo e Educação Física e Livre-Docência em Metodologia do Ensino de Educação Física. É professor do Departamento de Metodologia de Ensino da Faculdade de Educação da Universidade de São Paulo e coordena o Grupo de Pesquisas em Educação Física escolar Gpef - FEUSP/CNPq

E-mail:mgneira@usp.br 